\title{
Penetran Kalp Yaralanması: Olgu Sunumu \\ Penetran Kalp Yaralanması: Olgu Sunumu
}

\author{
Nuray ALTINDEĞER'1, Abdullah DOĞAN'1, illker AKAR', ilıer íNCE²
}

1 Gaziosmanpaşa Üniversitesi Tıp Fakültesi Kalp ve Damar Cerrahisi Anabilim Dalı, Tokat

2 Dışkapı Yıldırım Beyazıt Eğitim ve Araştırma Hastanesi, Kalp ve Damar Cerrahisi Kliniği, Ankara

\section{ÖZET}

Penetran kalp yaralanmaları genellikle delici-kesici alet ve ateşli silahlara bağlı meydana gelmektedir. Başvuru sırasında hastanın hemodinamik olarak stabil olması, kalp yaralanmasının gözden kaçmasına ve gerekli müdahalenin zamanında yapılamayarak hastanın kaybedilmesine neden olabilmektedir. Bu yazıda, 54 yaşında bir erkek olguda ateşli silah yaralanmasına bağlı olarak gelişen sol ventrikül yaralanmasının mediyan sternotomi ile başarılı bir şekilde tedavisi sunuldu.

Anahtar Kelimeler: Kalp, yaralanma, ateşli silah

\section{ABSTRACT}

Penetrating cardiac injuries usually occur due to stab and gunshot. On admission to emergency room, being stable hemodynamically can cause to overlook the cardiac injury and lead to the patient's loss because of not to perform the early intervention. In this article, successful treatment with median sternotomy of a 54-year-old male case with left ventricule injury due to gunshot was reported.

Key Words: Cardiac, injury, gunshot
Corresponding Author: Uzm. Dr. Nuray ALTINDEĞER

Adress: Gaziosmanpaşa Üniversitesi Tıp Fakültesi

Kalp ve Damar Cerrahisi AD 60100

E-mail: dr_nry2009@hotmail.com
Başvuru Tarihi/Received: 09-09-2015 Kabul Tarihi/Accepted: 11-11-2015 


\section{GiRiş}

Kalp yaralanmaları oluş şekline göre künt veya penetran olarak sınıflandırılabilir. Penetran yaralanmalar genellikle ateşli silahlar ve delici kesici alet yaralanmalarına bağlı meydana gelmektedir (1). Penetran yaralanmalarda sırasıyla en sık sağ ventrikül, sol ventrikül, sağ atrium ve sol atrium etkilenmektedir (2). Başvuru esnasında hastanın hemodinamik olarak stabil olması, kardiyak yaralanmanın gözden kaçmasına neden olabilmekte ve gerekli müdahalenin gecikerek hastada hayati tehlike ortaya çıkabilmektedir (3).

$\mathrm{Bu}$ yazıda hemodinamik olarak stabil olan, ekokardiyografik ve radyolojik olarak belirgin bulgu vermemesine rağmen sol ventrikül apeksi ve diagonal arter yaralanması ile sonuçlanan ateşli silah yaralanması olgusunu literatür eşliğinde irdelemeyi amaçladık.

\section{OLGU SUNUMU}

Elli dört yaşında erkek hasta acil servisimize toraks nafiz ateşli silah yaralanması nedeniyle getirildi. Genel durumu iyi, koopere, oryante idi. Kan basıncı 130/80 mmHg, kalp hızı 105/dakika idi. Sol hemitoraks 5. İnterkostal aralık midklaviküler hatta bir adet, sol hemitoraks posteriorunda 9. İnterkostal aralığın midskapular hattı kestiği yerde ve sağ skapula üzerinde bir adet olmak üzere toplam 3 adet ateşli silah yaralanmasına ait lezyon mevcuttu. Sağ skapula üzerinde palpasyonla mermi çekirdeği tespit edildi.

Hastanın acil serviste çekilen kontrastlı toraks bilgisayarlı tomografisinde minimal perikardiyal mayi saptandı (Resim 1), toraks içindeki vasküler yapılar ve kalpte belirgin patoloji yoktu. Sol hemitoraksta $8 \mathrm{~cm}$ kalınlığında hemotoraks saptandı ve bu tarafta akciğer parankim hasarı mevcuttu. Hastaya tüp torakostomi yapıldı ve $900 \mathrm{ml}$ hemorajik mayi geldi. Acil serviste yapılan transtorasik ekokardiyografide sağ ventrikül lateralinde minimal perikardiyal mayi saptandı.

Mermi giriş deliğinin lokalizasyonu ve hemotorak olması nedeniyle kardiyak yaralanma ekarte edilemediği için acil şartlarda operasyona alındı.

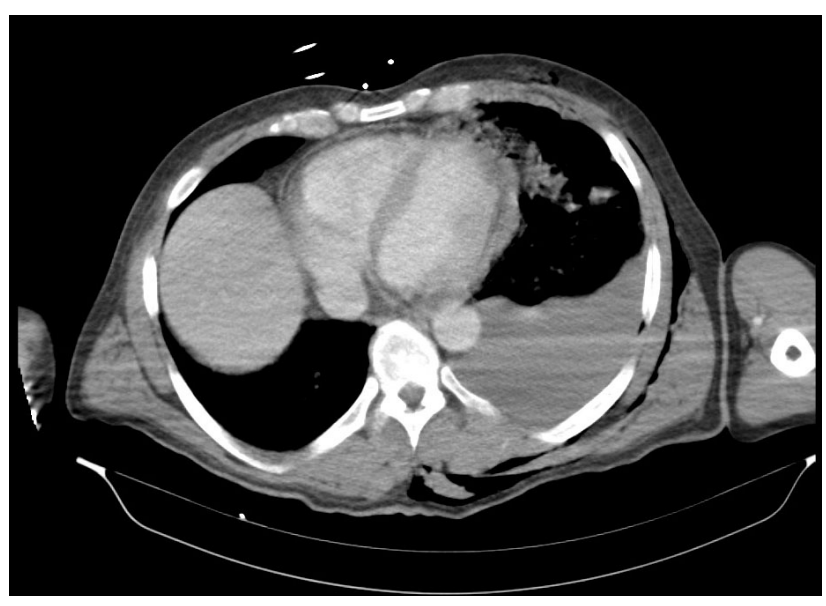

Resim 1: Preoperatif bilgisayarlı tomografi görüntüsü.

Genel anastezi altında median sternotomi yapılarak perikard açıldı ve kalbe ulaşıldı. Apeksin anterolateralinde yaklaşık $5 \times 3 \mathrm{~cm}$ boyutunda 1 $\mathrm{cm}$ derinliğinde laserasyon ve o bölgede diagonal arterin yaralandığı görüldü (Resim 2), ancak aktif kanama saptanmadı. Sol plevra açılarak toraksa ulaşıldı. Akciğer sol lobda yaralanma olduğu görüldü ve göğüs cerrahisi ekibi tarafından onarıldı. Sonrasında mevcut yaralanma kardiyopulmoner bypassa geçildi ve kross klemp koyuldu. Antegrad kan kardiyoplejisi ile diastolik arrest sağlandı. Mevcut yaralanmanın her iki kenarı teflon feltler ile desteklenerek defekt tamir edildi (Resim 3). Kross klemp alındı ve kalp spontan sinüs ritminde çalıştı. Kardiyopulmoner bypasstan çıkıldı, hasta dekanüle edildi. Mediastene bir adet drenaj tüpü yerleştirildi ve sternum çelik teller ile yakalaştırıldı. Sonrasında katlar anatomisine uygun olarak kapatıldı. Hasta entübe, inotropik destek olmaksızın yoğun bakım ünitesine transfer edildi. Hemodinamik olarak stabil seyreden hasta postoperatif 6 . Saatte ekstübe edildi. Postoperatif 2. Gününde servis takibine alındı. Hemodinamik olarak problem olmayan hasta 10. Günde taburcu edildi.

\section{TARTIŞMA}

Toraks yaralanmalarının \%70'i künt, \%30'u penetran yaralanmalardır (4). Penetran toraks yaralanmaları, delici kesici aletler ve ateşli silahlara bağlı olarak meydana gelmektedir. Gelişmiş ülkelerde ateşli silah yaralanmaları daha sık et- 


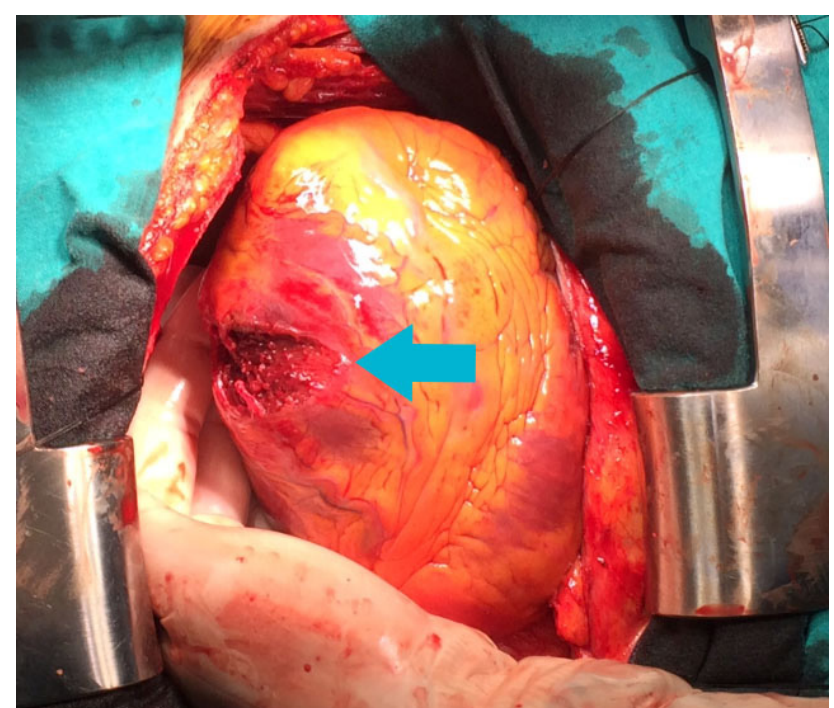

Resim 2: Sol ventrikül yaralanması intraoperatif görüntü.

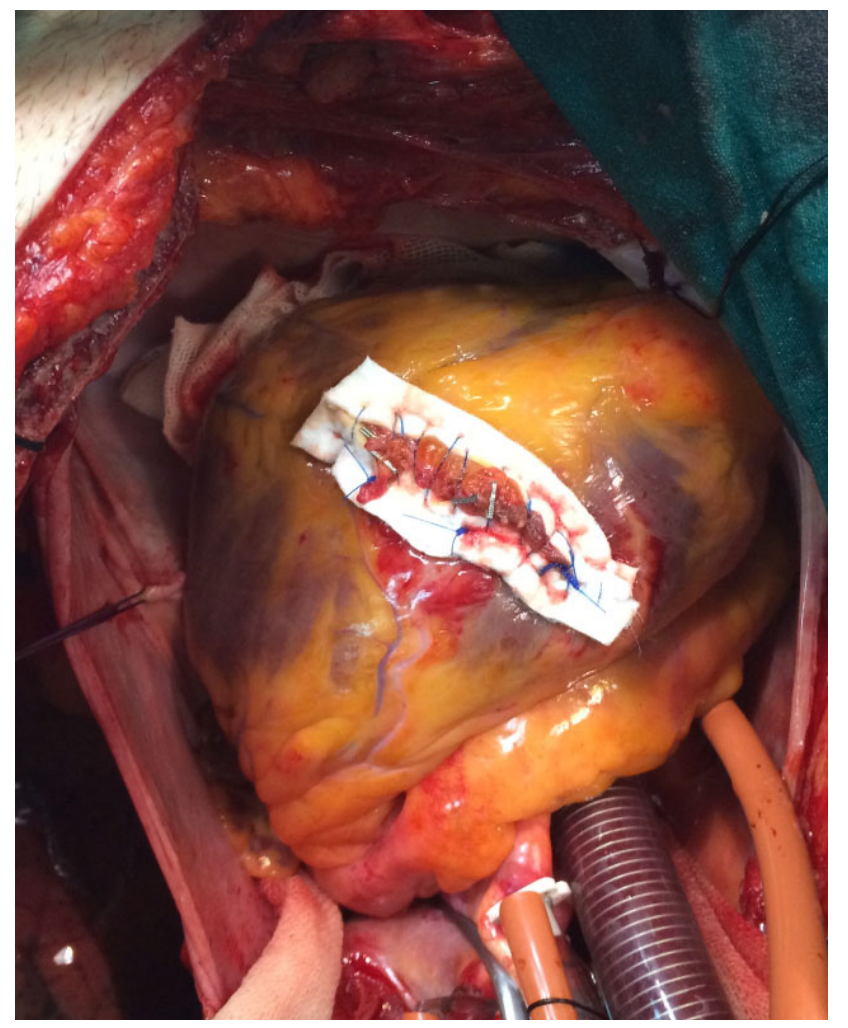

Resim 3: Tamir sonrası intraoperatif görüntü.

ken olmakla birlikte gelişmekte olan ülkelerde delici kesici alet yaralanmaları daha sık görülmektedir $(5,6)$.

Ateşli silah yaralanmalarında hastaların \%50'sinde müdahale gerektiren kardiyak yaralanma saptanırken, bunlarda mortalite \%40'lara ulaşmaktadır (7).

Penetran kardiyak yaralanmalarda sırasıyla en sık sağ ventrikül, sol ventrikül, sağ atrium ve sol atrium etkilenir. Serbest duvarlar daha sık etkilense de kapak yapılarında, papiller kaslarda, korda tendinealarda, atrial veya ventriküler septumda ve koroner arterlerde de hasar oluşabilir $(2,5,6)$. Bizim olgumuzda sol ventrikül ve diagonal arterde yaralanma mevcuttu.

Penetran kalp yaralanmalarında hızlı tanı ve tedavi mortaliteyi önler. Ölümlerin çoğu hastaneye transfer esnasında meydana gelmektedir. Hastanın klinik durumu; yaralanmanın şekline, hastaneye ulaşım süresine, ameliyata alınana kadar geçen süreye, ek yaralanma olup olmamasına ve kardiyak tamponadın olup olmamasına göre değişiklik gösterebilir (8). Hastaneye ulaşan ve hemen tanı konup zamanında operasyona alınan hastaların \%74'ü hayatta kalabilmektedir (9).

Ateşli silah yaralanmalarında kardiyak tamponad genellikle majör bulgudur. Tamponadın klinik bulgularının olması ve yaralanmanın lokalizasyonunun kalp trasesine uygun olması durumunda radyolojik inceleme yapılmadan hasta operasyona alınabilir (2). Bizim olgumuzda tamponad kliniği olmamasına, radyolojik ve ekokardiyografik olarak bulgu saptanmamasına rağmen yaralanmanın lokalizasyonunun kalp trasesine uygun olması itibariyle hasta acil olarak operasyona alındı.

Sol anterolateral torakotomi, sağ ve sol ventrikül ile pulmoner artere kolay ulaşım sağladığından hemodinamik olarak stabil olmayan hastalarda genellikle tercih edilen yaklaşım yöntemidir (10). Ancak kalp ve büyük damarlara erişimin daha kolay olması ve gerektiğinde kardiyopulmonere geçiş kolaylığı sağladığı için median sternotomi de tercih edilen bir diğer yaklaşımdır $(11,12,13)$. Biz de median sternotomiyi tercih ettik.

Atrial yaralanmalarda klemp uygulanarak primer sütürasyon yapılabilir. Basit miyokardiyal laserasyonlar tek tek dikişler ile miyokard tam kat geçilerek onarılabilir. Koroner arterlere yakın laserasyonlarda sütürler koroner arter akımına engel olmayacak şekilde geçilmelidir. Koroner arter yaralanmalarında koroner arterlere bypass gerekebilir. Çok büyük miyokardiyal yaralanmalarda kardiyopulmoner bypassa geçmek gerekebilir (14). Bu vakada miyokardiyal defektin büyük ol- 
ması nedeniyle onarım kardiyopulmoner bypass altında kalp arrest edilerek yapıldı. Diagonal arterdeki yaralanmanın arterin distalinde olması nedeniyle koroner bypassa gerek duyulmadı ve diagonal arter serbest uçları klipslenerek olası kanama kontrol altına alındı.

Penetran kalp yaralanmalarında kardiyak arrest gelişen ve acil müdahale edilen olgularda mortalite \% 54-94 oranında iken, arrest gelişmeden müdahale edilen olgularda bu oran \%13.5-40 arasındadır $(15,16,17)$. Hastamızın başvuru anında hemodinamisi stabil olmasına rağmen yaralanmanın lokalizasyonu nedeniyle acil operasyona alınarak gerekli kalp ve akciğer onarımı yapıldı.

Kalp yaralanmalarında mortaliteyi etkileyen en önemli faktör hastanın hastaneye en kısa sürede ulaştırılmasıdır. Hastaneye ulaşan tüm penetran prekordiyal yaralanmalar aksi ispatlanana kadar kardiyak yaralanma olarak değerlendirilmeli, hemodinamik açıdan stabil olsalar ve herhangi bir görüntüleme yöntemi ile kardiyak yaralanmaya dair bulgu saptanmamış olsa dahi yaralanmanın lokalizasyonu kalp trasesine uygun ise cerrahi girişimden kaçınılmamasının mortaliteyi azaltma yönünde önemli olacağı kanaatindeyiz.

\section{KAYNAKLAR}

1. Campbell NC, Thomson SR, Meumann CM, Van Middlekoop I, Botha JB. Review of 1198 cases of penetrating cardiac trauma. Br J Surg 1997;84:1737-40.

2. Karasu S, Tokat AO, Uzun HA, Kısacık E, Barlas AM, Boran NT. Penetran kalp yaralanmaları. Ankara Üniversitesi Tıp Faskültesi Mecmuası 2010;63:115-8.

3. Buchman TG, Philips J, Menker JB. Recognition, resusiscitation and management of patients with penetrating cardiac injuries. Surg Gynecol Obstetrics 1992;174:205-10.

4. Yalçınkaya İ, Kurnaz $M$, Çobanoğlu $U$ ve ark. Göğüs travması: 126 olgunun analizi. Ulusal Travma Dergisi 2000;6(4):288-91.

5. Akay T. Kalp ve damar yaralanmaları. TTD Toraks Cerrahisi Bülteni 2010;1:75-86.

6. Mataracı i, Polat $A$, Çevirme $D$, Büyükbayrak $F$, Şaşmazel A, Tuncer $E$, et al. Increasing number of penetrating cardiac trauma in a new center. Ulus Travma Acil Cerrahi Derg 2010;16:54-8.

7. Degiannis E, Benn CA, Leandros E, Goosen J, Boffard K, Saadia R. Transmediastinal gunshot injuries. Surgery 2000;128:416-22.

8. Kamalı S, Aydın MT, Akan A, Karatepe O, Sarı A, Yüney E. Penetrating cardiac injury:factors affecting outcome. Ulus Travma Acil Cerrahi Derg 2011;17:225-30.

9. Tyburski JG, Astra L, Wilson RF, et al. Factors affecting prognosis with penetrating wounds of the heart. J Trauma 2000;48:587-91.

10. Topaloğlu S, Aras D, Çağlı K, Ergun K, Deveci B, Demir $A D$, et al. Penetrating trauma to the mitral valve and ventricular septum. Tex Heart Inst J 2006;33(3):39295.

11. Johnson SB, Nielson JL, Sako EY. Penetrating intrapericardial wounds: clinical experience with a surgical protocol. Ann Thorac Surgery 1995;60:117-21.

12. Degiannis E, Bowky DM, Westaby S. Penetrating cardiac injury. Ann R Coll Surg Eng I 2005;87:61-3.

13. Mayrose J, Jehle DV, Mascati R, Lerner E, Brooke BA, Abrams BJ. Comparison of staples versus sutures in the repair of penetrating cardiac wounds. J Trauma 1999;46:441-3.

14. O'Connor J, Ditillo M, Scalea T. Penetrating cardiac injury. JR Army Med Corps 2009;155:185-90.

15. Attar S, Suter CM, Hankins JR, Sequeira A, McLaughlin JS. Penetrating cardiac injuries. Ann Thorac Surg 1991;51:711-5.

16. Asension AA, Berne JD, Demetriades $D$, et al. One hundred five penetrating cardiac injuries: A 2 year prospective evaluation. J Trauma 1998;44:1078-83.

17. Peter RM, Hugh $H$, Christoph $K$, et al. Penetrating cardiac injuries: A population based study. J Trauma 1998;45:366-70. 